microlithic industries in quartz found in Ceylon. Dr. Sankalia ("The Second Gujarat Prehistoric Expedition : A Preliminary Account of the Søarch of 'Microlithic Man in Gujarat',' by H. D. Sankalia and I. Karve, New Indian Antiquity, 7, No. 1; April 1944) has described the unearthing of some skeletons, believed to belong to the folk who made the pigmy objects described. Physical anthropologists will naturally await with interest a complete account of these finds when the final study of them has been made.

\section{Community Centres}

THE report on community centres recently prepared by the Ministry of Education (Pp. 40. London : H.M. Stationery Office. $9 d$. net) is a document of much importance. The Government has decided that the provision of such centres to promote the social and physical training and recreation of the community should be regarded as coming within the scope of the education service administered by local education authorities, such provision being covered by Section 53 of the Education Act, 1944, without prejudice to the power of other local education authorities under Section 4 of the Physical Training and Recreation Act, 1937, to provide centres for athletic, social or educational objects. Arising out of that decision, this report has been prepared at the instance of the Minister of Education by some of his officers, and is now published for general information. The first chapter of the report goes at once to the root of the matter. "During the present century, the day-today life of the British people has been profoundly affected by two parallel and closely related developments-the mechanisation of industry and a progressive reduction in working hours. The reduction in working hours may have been largely due to the growing demand for more leisure, but it was mechanisation which made it possible to meet the demand". That is the point of departure taken in this searching and comprehensive report; that, and another fact plain to be seen, that it is one thing to have spare time and another to know how to use it wisely. Though the report does not expressly say 30, it means that we have reached a position in which the twofold distinction between work and leisure should be replaced by a threefold distinction be. tween (1) work, done for a living, whether one likes it or not, (2) relaxation, play, recreation, for the recovery of poise, and (3) true leisure, spent upon pursuits which may make it in one way or another "the growing time of the spirit". In subsequent chapters the report goes into detail about the organization, staffing, provision and maintenance, and ownership, control and management of community centres. A valuable appendix sets forth the suggested sccommodation required for neighbourhood units in varying situations.

\section{Control of Rabies}

IN an interesting leading article, the Lancet (628, Nov. 11, 1944) directed attention to the need for the existing regulations designed to prevent the reintroduction of rabies into Great Britain. The law requires that all dogs imported, by air or otherwise, shall be quarantined for six months; strict insistence on this regulation would prevent the reappearance in Britain of this serious disease. Rabies is primarily a disease of dogs, cats and allied species ; but it is communicable to man and to domesticated animals by the bite of a 'mad' dog. It was first recorded in Great Britain in
A.D. 1000; but it probably existed here before that date. In the middle of the eighteenth century it raged among dogs in London and elsewhere. In the nineteenth century it broke out among several packs of fox-hounds, and some thirty-six persons a year died of rabies. By 1902 rabies had been eradicated from Great Britain by stringent control measures, and it did not reappear for sixteen years. By then (see Stockman, S., Vet. Record, 32, 135 ; 1929, quoted by the Lancet, loc. cit.) the public was so unfamiliar with the disease that some sections of it failed to realize the dangers of its reintroduction, and the abnormal conditions of that time doubtless helped its spread.

Rabies was found among dogs in Great Britain in September 1918, the infection having been brought in by smuggling dogs into the country by air. The Ministry of Agriculture took energetic measures against it, and these measures were helped by the fact that most of the dogs were affected by the dumb or paralytic form of the disease, which greatly restricts their wanderings and ability to bite, and also by the fact that the disease broke out in Cornwall, which is isolated to some extent from the rest of England; most of the affected dogs wandered west to the sea. Nevertheless, some seventeen counties became involved, 327 dogs died of the disease and 368 human beings were bitten and had to be treated. The outbreak was not controlled until December 1921 (see Lancet, ii, 719 ; 1926). In the United States, during the last ten years, there has been an average of fifty-seven cases a year, and some States have recorded more than a thousand cases a year among animals. Rabies vaccines are available, and the Lancet $(628$, Nov. 11, 1944) discusses the value of these, which has been questioned. Meanwhile it cannot be too widely known that rabies will, if it comes again to Great Britain, cause much suffering among men and animals. The quarantine regulations, which can keep rabies out of the country, should therefore be vigorously supported.

\section{Stars or Planets ?}

Peter van De Kamp has an article with this title in Sky and Telescope of December 1944, in which he deals with the question of the criterion for stars and planets - a matter of considerable importance in view of the fact that recent discoveries have shown the existence of 'planets' fifteen or twenty times the mass of Jupiter. He accepts Russell's critical value of 1/20 of the sun's mass as a conventional borderline between visible stars and the invisible bodies which can be designated as 'planets'. This criterion defines a planet or star, therefore, by its mass, not by its size. Among the methods for detecting unseen companions of low mass is the photographic method applied to nearby stars, and if the determination of the orientation of the perturbation orbit were sufficiently accurate, good results would be obtained. Difficulties arise from the fact that photographic star images are $1^{\prime \prime}-3^{\prime \prime}$ in diameter, and most of the recently discovered perturbations have a total amplitude of less than $0 \cdot 1^{\prime \prime}$. The gravitational method for discovering faint companions of low mass, while it is more powerful than the direct visual approach, has decided limitations for very low masses, and it would be extremely difficult by this method to find companion masses less than 1/100 times the sun's mass, even for the nearest stars. The star which seems unattended by dark companions may be the exception, and it is possible that the stars attended by massive companions, rather than by small planets, 